\title{
Выявление противоречий мировой финансовой системы и траектории экономического роста. Часть 1
}

\author{
Дарья Динец \\ Иркутский государственный университет путей сообщения, Иркутск, Россия
}

\section{Информация о статье}

Поступила в редакциию:

11.11 .2020

Принята

к опубликованию:

05.02.2021

удК 336.647/.648

JEL G17

\section{Ключевые слова:}

финансовый капитал, экономический рост, экономикофинансовые модели, фиктивный капитал

\section{Keywords:}

financial capital, economic growth, economic and financial models, fictitious capital

\begin{abstract}
Аннотация
Данная работа - первая часть серии статей, которые являются результатом научного поиска автора в части определения объяснительной силь взаимного влияния финансовой дестабилизаџии мирового хозяйства и потери драйверов экономического роста. В результате рассмотрения множества моделей роста, учитывающих и не учитываюшчих финансовые аспекты хозяйства, выявлено, что многие из моделей для обеспечения математической элегантности игнорируют объективные условия достижения экономического роста и развития. С другой стороны, выявлено, что государства, рынки и компании теряют субъектность в вопросах обеспечения экономического роста в результате нарастания финансовых противоречий глобальной экономики. На стыке выявленного субъектно-объектного диссонанса и строится настоящее исследование.
\end{abstract}

\section{Global Financial System Influence in Economy Growth Direction. Part 1}

\section{Darya Dinets}

\section{Abstract}

The paper's series is a result of author's science research in a field of define force in bilateral influence of global financial disability and economic growth drivers. As a result of growth models considering it was revealed a disappearing of growth and development objective conditions for the mathematical elegance achieve, no matter if there were financial parameters in the models. Besides, it was revealed the governments, markets ang companies have lost their subjectivity in growth achievement because of financial contradictions of the global economy. The research is based on contradiction of objective and subjective parameters of global growth and financial destruction. The first part is devoted to dissonance identify in growth models and its impossibility to provide and simulate of sustainability growth economy on the current conditions. An object of this research is the United States as a center of the global financial system. The second part is devoted to the globalization, financialization and informatization negative influence insights on global growth provide estimate. The particular attention was paid the "platforms capitalism" role on growth financialization process driving by the fictive capital. The research conclusions may be useful for the growth models 
actualization and for the economic and financial policies choose of the different economy subjects. The main trend of retrospective analysis is the financial and platform capitalism had spawned a lot of companies-leaders. For now, these companies on the first time on global history do not allow another market subject to achieve an economy growth. If nothing changes the global economy should choose between these companies or the capitalism at whole.

Актуальность заявленной темы определяется практико-методологическим и научным тупиком в процессе поиска и обоснования драйверов экономического роста как на глобальном, так и национальных уровнях. Замедление глобальных темпов роста проявлялось и до событий 2019-2020 гг., однако пандемия высветила ее наиболее «острые углы». Экономически развитые страны в результате глобальной рецессии постепенно переходят к модели конкуренции за ликвидность взамен моделей продуцирования экономического роста - это новая реальность, реализуемая тремя основными тенденциями: глобализацией, финансиализацией и цифровизацией. Игнорирование фундаментальных основ экономического роста в качестве единственно верной траектории развития глобальной экономики, переориентация на краткосрочные цели развития, борьбу за спекулятивные прибыли, поиск способов манипулирования информационной составляющей финансового рынка для присвоения больших спекулятивных прибылей - все это в совокупности предопределяет замедление темпов как технико-технологического, так и социально-экономического прогресса, что, в свою очередь, может привести к радикальным методам решения экономических проблем со стороны менее обеспеченных групп населения. О том, что проблема неравенства, во многом усугубляющаяся экспансией финансового капитала, транслируется в снижение темпов экономического роста, говорится много и часто, однако модели роста по большому счету игнорируют аспект важности анализа источников финансирования агрегированного спроса.

Основной целью данного цикла работ является выявление системных противоречий глобальной финансовой системы с позиции их влияния на траекторию глобального экономического роста за счет идентификации методологических и структурно-логических препятствий в процессе определения драйверов экономического роста. Полагаем, что верная интерпретация накопленного научного и практического опыта моделирования экономического роста с учетом реалий, задаваемых колоссальным дисбалансом глобальной воспроизводственной модели с явным перекосом в сторону финансового сектора, позволит актуализировать модели, с одной стороны, и нивелировать негативное воздействие процесса финансиализации на экономический рост - с другой.

Методологической основой данного исследования является критический анализ применимости известных моделей роста с точки зрения их адекватности сегодняшним реалиям. Результаты проведенного анализа путем «мысленного эксперимента» экстраполировались на реалии сегодняшнего дня для поиска эмпирических подтверждений выявленных противоречий.

Экономический рост определяется экономистами по-разному, но, чаще всего, говоря о росте, подразумевают увеличение подушевых величин выпуска или национального дохода. Теории роста иногда перемежаются с теориями цикла, последний часто ставят в краткосрочный противовес долгосрочным траекториям роста. Экономический принцип не слишком отличается от обывательского: зацикленность мешает росту, как в теоретических и методических выкладках, так и в долгосрочных эмпирических данных.

В книге Р. Барро «Экономический рост» [1] со ссылкой на Калдора приведены следующие эмпирические закономерности роста: 
1) выпуск на душу населения растет со временем, а его темп прироста не уменьшается;

2) физический капитал на одного работника растет со временем;

3) норма доходности капитала примерно постоянна;

4) отношение физического капитала к выпуску примерно постоянно;

5) доли труда и физического капитала в национальном доходе примерно постоянны;

6) темп роста выпуска на одного работника варьирует в значительной степени в различных странах.

Обсуждение экономического роста невозможно без поиска ответа на вопрос о том, почему одни страны растут быстрее других. Для объяснения ускоренного роста восточных стран над западными лидерами в теории роста используется термин «условной сходимости», означающий, что чем дальше экономика страны находится от своего стационарного состояния, тем быстрее она будет расти. Это означает, что потенциал роста играет более важную роль в скорости изменений, нежели накопленное страной богатство. Теория представляется спорной, как спорно и само наличие устойчивого стационарного состояния, в котором все макроэкономические показатели растут одинаковым темпом.

Теории и модели экономического роста, в первую очередь, неоклассические и неоинституциональные, а также обширный математический аппарат этих теорий сходятся в том, что рост обеспечивается технологией, ростом населения и ростом уровня знаний и навыков (в совокупности именуемых человеческим капиталом), а также качеством институтов [1]. По мере усиления капиталистических отношений между странами и группами стран в качестве источников роста также называют международную торговлю и международное движение капиталов. Признаком экономического роста считается изменение структуры экономики в пользу так называемого «третичного» сектора - сферы высокомаржинальных услуг, например, финансовых. Считается, что чем больше населения занято в третичном секторе, тем выше темпы экономического роста за счет накопленного богатства - при росте уровня богатства индивиды меньшую долю доходов тратят на товары. При этом чем выше уровень технического прогресса, тем меньше зависимость благосостояния от первичного сектора, связанного с природными ресурсами, а частности, с сельским хозяйством. Здесь также видится противоречие, поскольку уровень физического здоровья населения страны, который находится в прямой зависимости от уровня продовольственной безопасности, который, в свою очередь, зависит от развития сельского хозяйства в стране, не может не сказываться на темпах экономического роста, тогда как любая модель покажет рост при сокращении доли сельского хозяйства в пользу фармацевтической или химической промышленности, при том, что последние могут получать государственную поддержку.

Математические выкладки, заложенные в моделях роста, отчасти напоминают те же построения для анализа рисков. Напомним, что в 2008-2009 гг. в научной литературе было принято сокрушаться на предмет неработоспособности моделей прогнозирования рисков финансового рынка. Полагаем, что и с математикой экономического роста может произойти нечто подобное, когда окажется, что ни одна из моделей не способна объяснить траектории роста, а, тем более, предложить инструментарий для его ускорения.

Основные причины неработоспособности математического аппарата в деле прогнозирования роста видятся в следующем.

1. Нереалистичные допущения всех моделей. Наиболее часто встречающиеся допущения и условия, в которых применим математический аппарат 
неоклассических моделей роста, включает бесконечную жизнь домохозяйств, четкое разделение экономики на несколько не пересекающихся секторов, единую процентную ставку для всех агентов, абсолютную мобильность, либо, напротив, закрытость экономики, сходный уровень квалификации рабочей силы и т.д., что фактически ни в одной экономике не встречаются даже в краткосрочном периоде.

2. Игнорирование внешних «экстерналий», попытки включения в модели многих факторов в качестве эндогенных, то есть, задаваемых в самой модели. С одной стороны, понятно желание исключения шоков делового цикла из моделей долгосрочного роста, с другой - в тот исторический период, когда рост на длительный период подрывается внешними факторами, которые не заложены ни в одну модель, их игнорирование приводит к еще более нереалистичному представлению данных в модели [2]. К примеру, финансовый кризис, зародившись в сфере банковской ликвидности, теоретически не может быть учтен в моделях роста, однако фактические противоречия, которые накапливались в мировой финансовой системе и вылились в форме кризиса, должны были сказаться на прогнозах экономического роста, однако этого не произошло.

3. Потеря экономического содержания за математической сложностью и попытками поиска элегантных решений. К примеру, в модели роста, основанной на наличии технологического лидера отрасли [1], успех технологических инноваций оценивается как рыночная стоимость фирмы-лидера, осуществляющего инновационные разработки. Стоимость в модели определяется как отношение капитализируемых затрат на НИОКР (нематериальных активов) к вероятности успеха разработок. Знания математики начального уровня достаточно, чтобы понять, что чем больше фирма тратит на исследования и разработки, чем большая часть этих трат оседает на балансе в качестве элементов нематериальных активов (числитель), и чем ниже вероятность успеха разработок (знаменатель), тем выше будет рыночная стоимость фирмы-новатора. Эмпирические подтверждения данной формулы несложно встретить среди высокотехнологичных компаний, а, в особенности, стартапов, однако полагаем, что описанная зависимость не может выступать в качестве фактора экономического роста в долгосрочной перспективе.

4. Свойство, вытекающее из предыдущего пункта - способ измерения переменных в моделях и измеримость таковых. К примеру, не вполне понятно, каким образом можно измерить изменения в технологиях, каким образом ранжировать технологии в зависимости от того, на что направлено их внедрение и каковы масштабы вносимых изменений. Во-вторых, если рост измеряется стоимостными показателями, даже скорректированными на уровень инфляции, необходимо оценивать сопоставимость и устойчивость единиц стоимости.

5. Общий подход применения математических методов в экономике сегодня таков, что вначале отыскивается математически верное и представляющее для исследователя интерес решение, а затем под это решение «подводится» статистика. При этом для обоснования верности решения статистические данные «очищаются» от внешних эффектов, обобщаются, нормализуются, и подвергаются массе других операций, полностью обезличивающих экономические отношения, стоящие за теми или иными цифрами статистики. Иными словами, в попытке очистить данные от «случайностей», не влияющих на общую динамику роста, фактически достигается очищение математики от фактической, стоящей за безликими цифрами экономики.

6. Кроме того, при нереалистичности результатов применения моделей в них могут быть добавлены фиктивные переменные, либо введены новые допущения, при которых решение оказывается верным. К примеру, при исследовании эмпирических данных о темпах экономического роста в работе Р. Барро [1] высокой 
объясняющей силой обладала фиктивная переменная «отнесение к азиатским странам», что не позволяет определить, какие именно ключевые особенности экономического развития азиатских стран позволили им достичь более высоких темпов роста. Также большинство неоклассических моделей, учитывающих в построениях капитал, оказываются неработоспособными при проверке эмпирическими данными, если речь идет о физическом капитале - зданиях, машинах, оборудовании и т.д. [1] Для того, чтобы модели эндогенного роста работали и имели предиктивную способность, в качестве капитала рассматривается совокупность физического и человеческого капиталов, притом, что последний не имеет строгого теоретико-методического способа измерения и анализа, и делается допущение, что человеческий капитал относится к совокупному капиталу в пропорции 5/8. Во-первых, сама концепция человеческого капитала в данном случае оспорима, поскольку способность к квалифицированному труду отделена от рабочей силы, а во-вторых, даже если допустить такое теоретическое построение, весьма сомнительно, что заданная пропорция выполняется хотя бы в одной стране, а тем более - во всех странах.

7. Не вдаваясь в полемику на предмет целесообразности включения в модели человеческого капитала (отдельно от рабочей силы), считаем нужным отметить два следствия такого представления моделей роста. Во-первых, включение человеческого капитала в капитал в широком смысле вносит погрешность в расчет равновесной процентной ставки. То, что было бы реалистичной ставкой для физического капитала, при расширении базы начисления процента занижает ставку для экономики в целом. В таком случае процент перестает оказывать влияние на склонность к сбережению, и последняя становится экзогенным фактором в моделях роста, чего так стремятся избежать многие исследователи в данной области. Во-вторых, широкое представление капитала означает, что по мере его роста отдача начинает сокращаться. Однако У. Истерли [3] на основе анализа эмпирических данных и без использования математических моделей доказывает, что рост возможен только при наличии синергии в развитии навыков работников. Если работник обеспечен всеми необходимыми технико-технологическими средствами и осуществляет трудовую деятельность в сфере высококвалифицированных коллег, то рост его профессионализма окажет положительное влияние на доходы и выпуск, повышая благосостояние всех причастных. Если же работник, повышая квалификацию, может добиться лишь карьерного роста в ущерб другому работнику, то эта ротация чаще всего к росту не приводит. Иными словами, если повышение квалификации работника ведет к отрицательной отдаче от капитала в широком смысле, то это не рост, а перераспределение.

8. Отсутствие возможности оценки условий, при которых те или иные факторы повлияли на достижение экономического роста. Во-первых, условия могут не повториться, а политические решения, принимаемые для стимулирования роста, скажутся только на государственных расходах, не приводя к росту. Во-вторых, совместное воздействие нескольких факторов на темпы экономического роста при условии математической «подготовки» эмпирических данных к включению в модель многократно очищает такую модель от реальных внешних шоков, в которых совместное влияние факторов привело к некоему результату. То есть, при исследовании влияния нескольких факторов математическими методами на основе «очищенной» статистики теряется системность экономики, связи между элементами экономической системы, как правило, не включаются в модель.

9. Ввиду потери системных связей часто возникает путаница между причиной и следствием. Например, в теориях роста, учитывающих миграцию населения, имеется вывод о том, что чем выше уровень чувствительности миграционных 
потоков к затратам на переезд, тем выше уровень сходимости стран по темпам экономического роста. Полагаем, что связь здесь строго обратная: между странами со схожими темпами роста и факторами, рост определяющими, потоки мигрантов будут сильно зависеть от затрат на смену места жительства. Если же речь идет о переезде из страны с крайне низкими темпами роста в страну с высоким потенциалом развития, то затраты на переезд могут играть куда меньшую роль в принятии решения мигрировать. Иначе говоря, если речь идет о возможности кардинальной смены образа жизни, затраты на переезд не могут стать решающим фактором при принятии соответствующего решения.

10. Слабые возможности оценки уровня институтов. Качественные показатели, характеризующие уровень развития институтов, с позиции их влияния на экономический рост, включаются в модели эндогенного роста в качестве фиктивных переменных, либо косвенно за счет использования рейтингов развития различных стран. При этом использование рейтингов чревато автокорреляцией остатков, а использование фиктивных переменных не всегда способно оценить количественно степень влияния того или иного института на уровень экономического роста.

Также следует отметить, что математические методы во все времена имели ограниченную объясняющую силу в сложных экономических процессах, теперь же, в условиях финансиализации большинства развитых экономик и учащения появления на рынках финансовых пузырей. При распространении арбитража на финансовых рынках экстерналии, задаваемые финансовыми потоками, представляются настолько существенными, что игнорирование их в моделях роста равнозначно попытке прогнозирования будущего урожая без информации об объемах посевов.

Для более подробного анализа исследуемой проблемы обратимся непосредственно к описанию моделей роста (табл. 1).

Таблица 1

\section{Теории экономического роста}

\begin{tabular}{|c|c|c|}
\hline $\begin{array}{l}\text { Автор / } \\
\text { модель }\end{array}$ & Параметры модели роста & Влияние дополнительных факторов \\
\hline $\begin{array}{l}\text { Солоу } \\
\text { и Свэн }\end{array}$ & $\begin{array}{l}\text { Стационарный темп прироста } \\
\text { доходов на душу населения } \\
\text { равен темпу экзогенного эко- } \\
\text { номического прогресса. В } \\
\text { модели предполагается по- } \\
\text { стоянная отдача при измене- } \\
\text { нии масштабов производства }\end{array}$ & $\begin{array}{l}\text { Прогресс может быть нейтральным (по Хиксу), трудоинтен- } \\
\text { сивным и капиталоинтенсивным. } \\
\text { Долгосрочная тенденция к убыванию отдачи капитала может } \\
\text { быть нивелирована включением в модель человеческого капи- } \\
\text { тала }\end{array}$ \\
\hline $\begin{array}{l}\text { Харрод } \\
\text { и Домар }\end{array}$ & $\begin{array}{l}\text { Соотношение между обеспе- } \\
\text { ченным, реальным и эффек- } \\
\text { тивным ростом }\end{array}$ & $\begin{array}{l}\text { Экзогенная норма сбережения приводит к тому, что эконо- } \\
\text { мика останавливается на одном из нежелательных состояний: } \\
\text { рост безработицы, либо рост простаивающего оборудования }\end{array}$ \\
\hline Рамсей & $\begin{array}{l}\text { Эндогенная норма сбереже- } \\
\text { ний, эндогенный технологи- } \\
\text { ческий прогресс }\end{array}$ & $\begin{array}{l}\text { Чем выше уровень налогов на капитал, тем ниже склонность к } \\
\text { сбережению. } \\
\text { Предельная норма замены между правительственными и част- } \\
\text { ными расходами, которая возрастает со временем с темпом } \\
\text { прироста работоспособного населения. } \\
\text { Чем более конкурентны общественные услуги, тем меньше } \\
\text { стремление индивидов сберегать. } \\
\text { Совершенствование прав собственности способствует накоп- } \\
\text { лению капитала. } \\
\text { Дополнительный ввод капитала и издержки инвестирования } \\
\text { зависят от рыночной стоимости фирмы в отношении к стоимо- } \\
\text { сти ее капитала (при условии постоянной отдачи от масштаба } \\
\text { и эффективного фондового рынка). } \\
\text { Уровень издержек ввода инвестиций в эксплуатацию сокра- } \\
\text { щает предельные инвестиции. }\end{array}$ \\
\hline
\end{tabular}




\begin{tabular}{|c|c|c|}
\hline & & $\begin{array}{l}\text { Помимо амортизации и износа возникает дополнительное } \\
\text { обесценение капитала за счет роста квалификации рабочей } \\
\text { силы и внедрения новых технологий. }\end{array}$ \\
\hline $\begin{array}{l}\text { АК-мо- } \\
\text { дель }\end{array}$ & $\begin{array}{l}\text { Развитие неоклассической } \\
\text { модели Солоу за счет вклю- } \\
\text { чения в капитал не только } \\
\text { физической компоненты, но } \\
\text { и человеческого капитала }\end{array}$ & $\begin{array}{l}\text { Долгосрочный темп роста зависит от параметров, которые } \\
\text { определяют склонность к сбережению и производительность } \\
\text { капитала: «Снижение эластичности потребления и межвре- } \\
\text { менной нормы замещения, увеличивая склонность к сбереже- } \\
\text { нию, приводит к более высоким темпам прироста подушевого } \\
\text { дохода и к более высокой номе сбережения. Улучшение в } \\
\text { уровне технологии увеличивает средний и предельный про- } \\
\text { дукты капитала, а также поднимает темп прироста и изменяет } \\
\text { норму сбережения» }\end{array}$ \\
\hline $\begin{array}{l}\text { Эрроу, } \\
\text { Ромер, } \\
\text { Лукас }\end{array}$ & $\begin{array}{l}\text { Модели с эндогенным ро- } \\
\text { стом, исключающие убываю- } \\
\text { щую отдачу капитала за счет } \\
\text { эффектов распространения } \\
\text { знаний (опыта). } \\
\text { Согласно модели если отдача } \\
\text { капитала падает не ниже не- } \\
\text { которого положительного } \\
\text { значения, долгосрочный тем } \\
\text { роста зависит от уровня тех- } \\
\text { нологии и склонности к сбе- } \\
\text { режению }\end{array}$ & $\begin{array}{l}\text { Создание знаний является побочным продуктом инвестиций. } \\
\text { Чем выше объем физического капитала, тем больше навыков в } \\
\text { сфере управления производительностью. } \\
\text { Рост патентной активности приводит к росту инвестиций в } \\
\text { физический капитал. } \\
\text { Правительство может субсидировать рост инвестиций для } \\
\text { того, чтобы частная доходность соответствовала обществен- } \\
\text { ной. } \\
\text { Рост зависит от масштаба распространения технологий, эф- } \\
\text { фект масштаба производства и уровень перегрузки обществен- } \\
\text { ных услуг. } \\
\text { В модели накопления человеческого капитала упор сделан на } \\
\text { то, что рост человеческого капитала может скомпенсировать } \\
\text { отставание в технологическом развитии с точки зрения влия- } \\
\text { ния на экономический рост с учетом того, что уровень конку- } \\
\text { рентности человеческого капитала существенно выше уровня } \\
\text { конкурентности новых технологий. } \\
\text { В модели Ромера источником эндогенного роста является } \\
\text { число разработчиков, занятых в инновационном секторе и эф- } \\
\text { фективность их труда. Фактором снижения темпов экономиче- } \\
\text { ского роста считается нерациональное распределение трудо- } \\
\text { вых ресурсов между производством и инновационно-исследо- } \\
\text { вательским сектором, что усугубляется внешними эффектами } \\
\text { исследовательской деятельности. }\end{array}$ \\
\hline $\begin{array}{l}\text { Узава, } \\
\text { Лукас }\end{array}$ & $\begin{array}{l}\text { Двухсекторная модель, в со- } \\
\text { ответствии с которой при } \\
\text { производстве человеческого } \\
\text { капитала используется } \\
\text { только человеческий капитал, } \\
\text { а в производстве использу- } \\
\text { ется физический и человече- } \\
\text { ский капитал }\end{array}$ & $\begin{array}{l}\text { Человеческий капитал может перемещаться между образова- } \\
\text { нием и производством в соответствии с уровнем заработных } \\
\text { плат. Перемещения человеческого капитала влияют на отдачу } \\
\text { физического капитала и результативность изменения техноло- } \\
\text { гий, тем самым объясняя пропорции экономического роста в } \\
\text { системе в целом. } \\
\text { Дисбаланс в структуре капитала приводит в случае дефицита } \\
\text { физического капитала к росту потребления, а дисбаланс, свя- } \\
\text { занный с нехваткой человеческого капитала - к росту инвести- } \\
\text { ций. } \\
\text { В модели рост относительного количества физического капи- } \\
\text { тала приводит к увеличению темпа прироста человеческого } \\
\text { капитала и тем меньше темп прироста физического капитала. } \\
\text { Модель прогнозирует более существенное влияние на эконо- } \\
\text { мический рост человеческого, а не физического капитала. } \\
\text { Рост заработных плат приводит к сокращению темпов эконо- } \\
\text { мического роста. } \\
\text { Скорость экономического роста тем выше, чем больше раз- } \\
\text { ница между отношением физического и человеческого капи- } \\
\text { тала и стационарным состоянием этого отношения }\end{array}$ \\
\hline Барро & $\begin{array}{l}\text { Модели растущего разнооб- } \\
\text { разия товаров. } \\
\text { Эндогенный технологиче- } \\
\text { ский прогресс оценивается на } \\
\text { основании разработки новых } \\
\text { товаров и новых отраслей, } \\
\text { либо улучшении качества то- } \\
\text { варов }\end{array}$ & $\begin{array}{l}\text { Технологические изменения, происходящие за счет постоян- } \\
\text { ного увеличения номенклатуры производимой продукции, } \\
\text { позволяют устранить убывающую отдачу от факторов произ- } \\
\text { водства. } \\
\text { Основные факторы роста - это технологическая сложность } \\
\text { производимых товаров и степень специализации факторов } \\
\text { производства. } \\
\text { Сектор, занятый в производстве технологических нововведе- } \\
\text { ний - промежуточных товаров, стимулирует рост прибыли, } \\
\text { который складывается из нормы прибыли на капитал и приро- } \\
\text { ста стоимости самого бизнеса, что в совокупности не должно } \\
\text { быть ниже процентной ставки по кредитам, а в стационарном } \\
\text { состоянии равно этой ставке. }\end{array}$ \\
\hline
\end{tabular}




\begin{tabular}{|c|c|c|}
\hline & & $\begin{array}{l}\text { На темпы экономического роста оказывают влияние издержки } \\
\text { на разработку технологических инноваций и темп роста насе- } \\
\text { ления: чем больше экономика, тем ниже подушевые издержки } \\
\text { на инновации и тем сильнее эффект от их распространения } \\
\text { при условии трудоинтенсивного экономического роста. } \\
\text { На скорость распространения инноваций влияет уровень па- } \\
\text { тентного права, в том числе, международного. } \\
\text { Согласно модели, правительство должно за счет налогообло- } \\
\text { жения и субсидирования стимулировать установление цен на } \\
\text { промежуточные инновационные товары на уровне предельных } \\
\text { издержек при сохранении стимулов к инновационной деятель- } \\
\text { ности. Либо вводить прямые субсидии на исследования и раз- } \\
\text { работки. } \\
\text { Падение монопольной прибыли новатора при распростране- } \\
\text { нии его идей на конкурентный рынок приводит к падению ры- } \\
\text { ночной стоимости бизнеса до нуля, то есть, в функции прави- } \\
\text { тельства входит нахождение компромисса между выгодами от } \\
\text { развития конкуренции и диффузии инноваций и стимулами } \\
\text { для новаторов к изобретениям в виде возможности получения } \\
\text { ими монопольной прибыли }\end{array}$ \\
\hline $\begin{array}{l}\text { Шумпе- } \\
\text { тер }\end{array}$ & $\begin{array}{l}\text { Модель изменения качества } \\
\text { производимых товаров }\end{array}$ & $\begin{array}{l}\text { По мере улучшения качества продукции новые товары и тех- } \\
\text { нологии со временем заменяют старые: «Исследователи, кото- } \\
\text { рые добиваются успеха в процессе улучшения качества ка- } \\
\text { кого-либо продукта, лишают монопольной ренты существую- } \\
\text { щего производителя данной продукции», поэтому фирмы вы- } \\
\text { нуждены осуществлять затраты на исследования и разработки } \\
\text { для сохранения рыночной стоимости бизнеса. На инновацион- } \\
\text { ную активность в отрасли оказывает влияние наличие лидера } \\
\text { по уровню издержек на исследования и разработки - наличие } \\
\text { подобного лидера позволяет ему аккумулировать отраслевой } \\
\text { объем технологических разработок, повышать свою моно- } \\
\text { польную власть и сокращать уровень общественных выгод, а, } \\
\text { тем самым, через механизм затрат оказывать негативное влия- } \\
\text { ние на экономический рост. } \\
\text { В модели предполагается, что чем выше затраты на исследова- } \\
\text { ния и разработки, тем выше вероятность успеха в изготовле-- } \\
\text { нии товара более высокого качества. При этом вероятность ро- } \\
\text { ста качества за счет исследований и разработок определяетяя } \\
\text { уже достигнутым новатором уровнем инновационности и тех- } \\
\text { нологичности. }\end{array}$ \\
\hline Истерли & $\begin{array}{l}\text { Трудосберегающий техноло- } \\
\text { гический прогресс как источ- } \\
\text { ник экономического роста }\end{array}$ & $\begin{array}{l}\text { Наличие «ловушек» (капканов бедности), утечек (развития за } \\
\text { счет обучения на передовом опыте) и соответствий (возмож- } \\
\text { ность и целесообразность получения качественного образова- } \\
\text { ния и повышения квалификации соответствуют накопленному } \\
\text { опыту. Так, если уровень здравоохранения в стране низок, то } \\
\text { получение квалификации доктора окажется непривлекатель- } \\
\text { ным для молодого человека, выбирающего профессию). } \\
\text { Закон убывающей отдачи не действует, если новая техника } \\
\text { появляется одновременно с новой технологией. Уровень сбе- } \\
\text { режений создает избыток капитала при невозможности его эф- } \\
\text { фективного размещения, и не приводит к экономическому ро- } \\
\text { сту }\end{array}$ \\
\hline Браун & $\begin{array}{l}\text { Теория роста с возможно- } \\
\text { стью перемещения капитала } \\
\text { и миграцией. Уровень техно- } \\
\text { логий определяет направле- } \\
\text { ния потоков капитала и рабо-- } \\
\text { чей силы между странами }\end{array}$ & $\begin{array}{l}\text { Убывающая отдача капитала, время на распространение тех- } \\
\text { нологий и издержки копирования технологий между странами } \\
\text { в сравнении с издержками на исследования и разработки сдер- } \\
\text { живают перемещение капитала и рабочей силы между стра- } \\
\text { нами. }\end{array}$ \\
\hline Ростоу & $\begin{array}{l}\text { Стадии развития от традици- } \\
\text { онных (аграрных) форм до } \\
\text { высокого уровня массового } \\
\text { потребления и поисков ис- } \\
\text { точников духовного роста че- } \\
\text { ловечества }\end{array}$ & $\begin{array}{l}\text { Рост национального производства - рост богатства - рост ка- } \\
\text { чества жизни }\end{array}$ \\
\hline $\begin{array}{l}\text { Ченери, } \\
\text { Бруно, } \\
\text { Страут }\end{array}$ & $\begin{array}{l}\text { Теория эндогенного роста с } \\
\text { использованием внешних фи- } \\
\text { нансовых ресурсов }\end{array}$ & $\begin{array}{l}\text { Дефицит сбережений и торговый дефицит могут покрываться } \\
\text { за счет внешних заимствований, которые обеспечивают эконо- } \\
\text { мический рост }\end{array}$ \\
\hline Льюис & $\begin{array}{l}\text { Экзогенная модель роста. } \\
\text { Оценка избыточного роста } \\
\text { трудоспособного населения }\end{array}$ & $\begin{array}{l}\text { Норма прибыли на капитал обратно пропорциональна избытку } \\
\text { рабочей силы }\end{array}$ \\
\hline
\end{tabular}




\begin{tabular}{|c|c|c|}
\hline $\begin{array}{l}\text { Фей, } \\
\text { Ранис }\end{array}$ & $\begin{array}{l}\text { Модель эндогенного роста с } \\
\text { тремя секторами, каждый из } \\
\text { которых представляет ре- } \\
\text { сурсы для функционирования } \\
\text { другого. В итоге процесс кру- } \\
\text { гооборота включает в себя } \\
\text { последовательные и парал- } \\
\text { лельные обмены между раз- } \\
\text { личными секторами }\end{array}$ & Межсекторный обмен как основа экономического роста \\
\hline
\end{tabular}

Источник: составлено автором на основании $[1,2,4,5,6,7,8,9,12,13]$

Из табл. 1 видно, что, по мнению Ф. Рамсея происходит дополнительное дисконтирование стоимости инвестиций за счет увеличения уровня квалификации работников и внедрения новых технологий. Однако если предположить синергетический эффект, то на фазе активного роста и технологии, и рост квалификации должны приводить к росту рыночной стоимости капитала фирм. В самой модели заложена обратная логика: если начальная рыночная стоимость капитальных вложений высока (отношение value / cost), то это стимулирует к дальнейшему росту инвестирования, однако фактически такая ситуация зачастую является признаком рыночных спекуляций с активами. Если к этому добавляются финансовые спекуляции и операции с производными финансовыми инструментами, то в результате может возникнуть полноценный финансовый пузырь.

Также в исследовании теории имеются выводы о скорости условной сходимости между богатыми и бедными экономиками: «бедная экономика с доступом к мировому рынку кредита будет иметь высокую стоимость введенного капитала и высокий темп прироста объема капитала» [1], что фактически означает, что стоимость капитала будет тем более завышенной, чем ниже исходный уровень фондовооруженности экономики. Такая ситуация вполне реальна и зачастую наблюдаема: цены на новый (или относительно) новый капитал в бедных экономиках бывают сильно завышены, как минимум по причине необходимости дисконтирования по высоким процентным ставкам и из-за непрозрачности ценообразования, либо отсутствия конкуренции (например, цена мобильной связи в африканских странах). В результате мы получаем локальный ценовой пузырь, никак не связанный с экономическим ростом, более того, ни о какой условной сходимости подобные ситуации говорить не могут, поскольку являются либо следствием спекуляций, либо инструментом выкачивания ресурсов транснациональным бизнесом, когда речь идет о меньших издержках ввода инвестиций в эксплуатацию в более бедных странах.

В модели Рамсея предполагается, что уровень процентных ставок на мировом кредитном рынке должен превышать сумму темпов прироста технологических инноваций и населения [10]. Представляет несомненный интерес исследование этой зависимости.

Предположим, что это условие не соблюдается, и процентная ставка на мировом рынке ниже указанных темпов прироста в какой-то стране. В пространстве финансового капитала это означает, что страна, оказавшаяся в такой ситуации, начнет рефинансировать ранее принятые обязательства, а это, в свою очередь, приведет к росту показателей окупаемости уже имеющегося капитала, заметим, без фактического роста его производительности. Если исследуемая страна имеет развитый фондовый рынок, это также приведет к росту капитализации на нем, что подстегнет инвестиции в традиционные отрасли и сократит темп роста инноваций, как минимум, до уровня мировых процентных ставок. Таким образом, искусственно низкий процент оказывает понижательное воздействие на темпы инновационной активности за счет роста разрыва между финансовым капиталом и процессом расширенного воспроизводства. Более того, представляется что 
обозначенный механизм может выступать инструментом манипулирования центра мировой финансовой системы над инновационной активностью ее периферии: колебания доходности уже осуществленных инвестиций способны перенаправлять финансовые потоки между отраслями.

Если при этом процентные ставки таковы, что приведенная стоимость будущих потоков доходов несущественно отличается от их номинала, то эластичность межвременного предпочтения возрастает, и уровень инвестиций соответствующим образом сокращается. В теории моделей роста, в частности, рассматриваемой модели Рамсея, это говорит о том, что уровень потребления в будущих периодах в таком случае сокращается, однако фактически это имеет крайне разные последствия для центра и периферии мировой финансовой системы. Если в центре уровень потребления никах не зависит от межвременных предпочтений прошлого, то периферия вынуждена «оплачивать» этот рост потребления своим потенциалом экономического роста. Более того, фактически возникает ситуация разрушения экономических основ деятельности национального хозяйства, экономическая целесообразность и долгосрочные цели развития уступают место мгновенным выгодам и «косметическим» решениям, нацеленным на решение локальных несущественных в масштабах мирового хозяйства задач [11].

Например, возьмем текущую экономическую ситуацию, спровоцированную пандемией. Она уже показала ущербность экономического роста, основанного на цифровой трансформации, обнаружив все признаки если не экономической депрессии, то рецессии, при падении объемов торговли продукцией традиционных отраслей, включая отрасли услуг. Представляется, что на фоне снижения активности целесообразно реализовать проекты, которые ранее откладывались из-за нехватки ресурсов, мощностей, времени, территорий, а сейчас, когда все перечисленные факторы в избытке, «новый курс. 2.0» ${ }^{1}$ смог бы инфраструктурно подготовить экономику к будущим изменениям без искусственного ограничения деятельности существующих отраслей. Однако фактически этого не происходит. К примеру, Правительство РФ внесло в Государственную думу поправки в Налоговый кодекс ${ }^{2}$ о проведении так называемого налогового маневра в ITотрасли, для представителей которой предлагается установить налоговую ставку по налогу на прибыль в размере 3 \% (сократив часть, уплачиваемую фирмами в региональные бюджеты, до нуля). Ожидается, что это повысит привлекательность российских технологий, приравняв условия их деятельности к индийским или ирландским. Возникает два закономерных вопроса: во-первых, с каких пор приобретение статуса конкурента индийским IT-компаниям стало перспективным путем развития экономики, а во-вторых, и это самое главное, зачем поддерживать одну из немногих отраслей, которая оказалась в выигрыше от пандемии?

Опыт преподавательской деятельности подсказывает, что студенты, обучающиеся на информационных специальностях, чаще других бросают учебу, так как, получив некие азы, углубляются в узкие области IT, зачастую десоциализируются, и теряют ощущение потребности в продолжении образования, что по цепной реакции приводит к снижению научного потенциала высшей школы и финансового обеспечения ее деятельности.

Кроме того, информационные технологии и так называемая цифровая экономика, как бы то ни было, не производят материальных благ, без которых прогресс не так уж необходим. И, говоря о прогрессе, любые инновационные достижения в сфере IT должны иметь прикладной характер, решая и упрощая некие

\footnotetext{
${ }^{1}$ Новый курс 2.0 - условное название политики стимулирования совокупного спроса экономически развитыми странами с 2014 года (особую актуальность данная политика получила в условиях «коронакризиса»)

${ }^{2}$ https://www.vedomosti.ru/economics/articles/2020/06/22/833106-it-otrasl-poluchit-bessrochnii-nalogovii-stimul
} 
задачи воспроизводства физического капитала и обращения финансового капитала. Если же инновации в цифровой сфере первичны, то возникает вопрос, на что они направлены? На удешевление уже имеющихся в традиционной экономике процессов, на их видоизменение, ускорение, повышение мощности, изменение конфигурации и дизайна, то есть, максимум, на статус улучшающих инноваций по Шумпетеру [14].

Если оценить описанные тенденции в терминах модели роста Шумпетера [14], то можем предположить, что стимулирование развития отрасли спровоцирует рост числа исследователей в ней, что, согласно модели, приведет к росту качества выпускаемых продуктов и возникновению возможности установления монопольной цены агентами, внедряющими инновации. Скорость нововведений в данной отрасли систематически приводит к росту цен на так называемые цифровые инновации, что влечет за собой рост индивидуальных прибылей. Однако данная отрасль, будучи по сути своей инфраструктурной, может повысить общественную эффективность только при условии сокращения издержек других фирм на ее услуги, то есть, при условии снижения цен. Следовательно, подобные стимулы можно считать угрожающими экономическому росту.

В целом, следует отметить, что постоянное манипулирование в моделях средними, предельными, агрегированными, частными и общественными [15] (с учетом государственного сектора) значениями рассматриваемых в той или иной модели переменных создает возможности математического обоснования практически любой модели, как бы далеко она ни была от реальности экономических отношений на каждом конкретном историческом этапе развития мирового хозяйства и финансовой системы. Исследование темпов экономического роста без учета перераспределительных эффектов сводит на нет предлагаемые различными авторами математические выкладки.

Требования мгновенной доходности не должны превалировать в экономике над задачей обеспечения долгосрочного роста посредством технологического прогресса. В условиях, когда государство должно менять амортизационную политику средствами поправок в налоговый кодекс, поощряя ускоренную амортизацию капиталоемких производств и стимулируя тем самым производство средств производства, политика поддержки отрасли информационных технологий выглядит злой насмешкой.

Отсутствие экономического мышления на всех уровнях вертикали власти как на уровне хозяйствующих субъектов, так и на уровне государственного и надгосударственного управления становится очевидным в сегодняшних условиях нарастания социально-экономических дисбалансов. Политичность принимаемых на всех уровнях решений, угодливость в чью-либо пользу, подстраивание под математические модели, которые, в свою очередь, «подогнаны» под описание эмпирических данных за определенный давно прошедший интервал времени - все это в совокупности не позволит мировому и национальному хозяйству переломить долгосрочные тренды на рост и развитие.

Не стоит забывать и о свойствах, отмеченных выше. Индустрия информационных технологий в части оборудования и информационных платформ порождается западными компаниями; полупроводниковое оборудование - это одна из основных статей американского экспорта [16], рост числа сборочных и обслуживающих фирм в России приведет к тому, что Россия увеличит свой вклад в оплату счетов западных стран за чрезмерное потребление. Иными словами, увеличивая доходность инвестиций в цифровые платформы за счет стимулирования ITбизнеса в своей стране, мы позволяем наращивать потребление в центре мировой финансовой системы в ущерб требованиям экономического роста за счет развития 
технологий. Чем больше стран включается в этот процесс, тем более иллюзорно выглядит вероятность относительной сходимости в темпах роста различных стран.

Интересно в этом ключе оценить и наблюдаемый ныне разрыв дипотношений между Китаем и США. Невозможность сохранения конкурентности разработок толкает США на угрозы и карательные меры за «неконкурентное» поведение китайских госкомпаний. Налицо очередной перекос между технологиями и финансами в ключе конкуренции за экономический рост: финансовый механизм компании в условиях полупроводниковой экономики исключает возможность сборки в «дорогих» странах, поскольку ни о какой окупаемости, а, тем более, экономическом росте говорить тогда не приходится [16]. В свою очередь, любые усовершенствования технологии в условиях международного аутсорсинга крайне быстро становятся неконкурентными, поэтому сохранять технологическое лидерство по завышенным ценам становится все труднее. Качество и бренд, таким образом, становятся все более дорогими в обслуживании, а, следовательно, для моделирования финансовых показателей становится необходимым и обязательным снижение процентных ставок, что, в свою очередь, не позволяет даже самим цифровым технологиям вырваться из эры полупроводников.

Кроме того, если следовать логике модели роста Эрроу [6], то только само производство позволяет накапливать опыт, необходимый для роста производительности - источника роста и окупаемости инвестиций. Таким образом, помимо дешевого труда производственные модели накапливают потенциал роста производительности, которая, будучи подкрепленной общедоступными технологиями, обеспечивает рост эффективности. Иными словами, формируются два полюса, на одном из которых сосредоточена ликвидность, а на другом - эффективность. В таких условиях синергия от взаимодействия капиталов в воспроизводственном процессе представляется невозможной: первый полюс будет страдать от дефицита финансового капитала, а второй - от низкой эффективности производства, а попытка перераспределения ресурсов между полюсами, вероятнее всего, приведет к финансовому кризису. Вероятно, по этой причине Китай жестко контролирует иностранные инвестиции, памятуя о восточных финансовых кризисах конца прошлого века. Попытки же повысить эффективность в странах-лидерах мировой финансовой системы, сталкиваясь с необходимостью сокращения затрат, начинают буксовать, поскольку любое сокращение затрат для одного агента означает сокращение доходов другого, а это, в свою очередь, отражается на ценах, снижение которых грозит в лучшем случае локальным обвалом финансового рынка. Последствия подобной схемы хорошо известны, в том числе, и с точки зрения падения темпов экономического роста [17].

Подобная полярность и отсутствие синергии в капиталах не оцениваются, и, полагаем, не могут быть оценены в математических моделях, описывающих экономический рост, поскольку это не вопрос специализации, это вопрос механизмов воспроизводства капитала.

В качестве предварительного итога и предвосхищения второй части настоящей работы вновь рассмотрим теорию У. Истерли [3]. Полагаем, что вывод о необходимости синергии может быть справедлив и для взаимодействующих экономик: если догоняющее развитие оценивается финансовыми лидерами как угроза финансовому благополучию, то вся мировая финансовая система таит в себе структурную неэффективность, которая выражается в замедлении темпов роста в долгосрочном периоде для всех ее участников, в том числе, и за счет чрезмерно конкурентных технологий. 


\section{Список источников / References}

1. Барро Р. Дж. Экономический рост / Р. Дж. Барро, Х. Сала-и-Мартин ; пер. с англ. - М. : БИНОМ. Лаборатория знаний, 2017. 824 с. [Barro R. Dzh. Ekonomicheskii rost / R. Dzh. Barro, Kh. Sala-i-Martin ; per. s angl. - M. : BINOM. Laboratoriya znanii, 2017. 824 s.]

2. Гамза В. А. Главная задача государства в экономике - формирование и развитие рынков // Контуры глобальных трансформаций: политика, экономика, право, 2008, № 1, c. 105-107 [Gamza V. A. Glavnaya zadacha gosudarstva v ekonomike formirovanie i razvitie rynkov // Kontury global'nykh transformatsii: politika, ekonomika, pravo, 2008, № 1, s. 105-107]

3. Истерли У. В поисках роста. Приключения и злоключения экономистов в тропиках / Уильям Истерли, 2006 г. 352 с. [Isterli U. V poiskakh rosta. Priklyucheniya i zloklyucheniya ekonomistov v tropikakh / Uil'yam Isterli, 2006 g. 352 s.]

4. Solow R. M. A contribution to the theory of economic growth // Quarterly Journal of Economics. 1956. № 70. Pp. 65-94.

5. Solow R.M. Growth theory: an exposition. Oxford: Oxford University Press. 1970. 109 p.

6. Romer P. Increasing returns and long run growth // Journal of political economy. 1986. № 94.

7. Lucas R. On the mechanics of economic development // Journal of monetary economics. 1988. № 22. Pp. 3-42.

8. Harrod R. Scope and Method of Economics // Economic Journal. 1938. № 48 (Sept.). Pp. 383-412.

9. Domar E. D. Essays in the theory of economic growth. N.Y.: Oxford University Press, 1957. $272 \mathrm{p}$.

10. Сорокин Д.Е., Сухарев О.С. Экономический рост: от неоклассики к институциональным трактовкам // Вестник Пермского университета. Сер. «Экономика»= Perm University Herald. Economy. 2016. № 4(31). C. 7-21. doi: 10.17072/1994-99602016-4-7-21 [Sorokin D.E., Sukharev O.S. The economic growth: from neoclassical economics to the institutional treatment // Vestnik Permskogo universiteta. Seria Ekonomika $=$ Perm University Herald. Economy. 2016. № 4(31). P. 7-21. doi: 10.17072/1994-9960-2016-4-7-21]

11. Домнич Е.Л. О добросовестности и достоверности статистики инноваций в промышленности России // Регионалистика. 2017. Т. 4. № 5. С. 76-91. DOI: 10.14530/reg.2017.5 [Domnich Ye.L. About Conscientiousness and Reliability of Innovation Statistics in Russian Industry. Regionalistica [Regionalistics]. 2017. Vol. 4. No. 5. Pp. 76-91. (In Russian) DOI: 10.14530/reg.2017.5]

12. Гераськин М. И., Порубова П. В. Дифференциальная модель макроэкономического роста с эндогенной цикличностью // Актуальные проблемы экономики и права. 2017. Т. 11, № 3. C. 43-55. DOI: http://dx.doi.org/10.21202/1993047X.11.2017.3.43-55 [Geras'kin M. I., Porubova P. V. Differentsial'naya model' makroekonomicheskogo rosta s endogennoi tsiklichnost'yu // Aktual'nye problemy ekonomiki i prava. 2017. T. 11, № 3. S. 43-55. DOI: http://dx.doi.org/10.21202/1993047X.11.2017.3.43-55]

13. Maddison A. Growth and Slowdown in Advanced Capitalist Economies: Techniques of Quantitative Assessment // Journal of Economic Literature. 1987. Vol. 25. P. 649-698.

14. Лукас, Р. Э. Лекции по экономическому росту / Р. Э. Лукас ; пер. с англ. Д. Шестакова. - М. : Изд-во Ин-та Гайдара, 2013. - 288 c. [Lukas, R. E. Lektsii po ekonomicheskomu rostu / R. E. Lukas ; per. s angl. D. Shestakova. - M. : Izd-vo In-ta Gaidara, 2013. - 288 s.]

15. Харрод, Р. К теории экономической динамики: новые выводы экономической теории и их применение в экономической политике / Р. Харрод. - М. : Изд-во иностр. лит., 1959 [Kharrod, R. K teorii ekonomicheskoi dinamiki: novye vyvody ekonomicheskoi teorii i ikh primenenie v ekonomicheskoi politike / R. Kharrod. - M. : Izd-vo inostr. lit., 1959] 
16. Варнавский В.Г. Роль США в мировой промышленности и торговле как глобальная проблема // Контуры глобальных трансформаций: политика, экономика, право. Т. 11. № 2. С. 100-112. DOI: 10.23932/2542-0240-2018-11-2-100-112 [Varnavskii V.G. Rol' SShA v mirovoi promyshlennosti i torgovle kak global'naya problema // Kontury global'nykh transformatsii: politika, ekonomika, pravo. T. 11. № 2. S. 100112. DOI: 10.23932/2542-0240-2018-11-2-100-112]

17. Стиглиц Дж. Люди, власть и прибыль: Прогрессивный капитализм в эпоху массового недовольства / Джозеф Стиглиц ; пер. с англ. - М. : Альпина-Паблишер, 2020. - 430 c. [Stiglits Dzh. Lyudi, vlast' i pribyl': Progressivnyi kapitalizm v epokhu massovogo nedovol'stva / Dzhozef Stiglits ; per. s angl. - M. : Al'pina-Pablisher, 2020. $-430 \mathrm{~s}$.

\section{Сведения об авторах / About authors}

Динец Дарья Александровна, канд. экон. наук, доцент, заведующий кафедрой экономики и управления на железнодорожном транспорте, Иркутский государственный университет путей сообщения. 664074 Россия, г. Иркутск, ул. Чернышевского, 15, каб. Л-310. E-mail: dinets_d_a@mail.ru Darya A. Dinets, Candidate of Economic Sciences, Associate Professor, Head of the Department of Railway Transport Economics and Management, Irkutsk State Transport University. Office L-310, 15 Chernishevsky str., Irkutsk, Russia 664074. E-mail: dinets_d_a@mail.ru 